\title{
A Letter to the Editor Regarding the Original Article by Costa et al: Psychological Support, Puberty Suppression, and Psychosocial Functioning in Adolescents with Gender Dysphoria
}

Michael Biggs, Department of Sociology, University of Oxford

Journal of Sexual Medicine, vol. 16, 2019, p. 2043

I read with interest the article by Costa et al, ${ }^{1}$ published in the Journal of Sexual Medicine, which investigates the effects of gonadotropin-releasing hormone analogs ( $\mathrm{GnRHa}$ ) to suppress puberty in adolescents suffering from gender dysphoria. According to the abstract, "adolescents receiving also puberty suppression had significantly better psychosocial functioning after 12 months of GnRHa ... compared with when they had received only psychological support." The literature now treats this article as providing evidence in favor of puberty suppression. ${ }^{2,3}$

The article analyzes 201 adolescents diagnosed with gender dysphoria. The outcome is psychosocial functioning measured by the Children's Global Assessment Scale (CGAS), administered four times over 18 months. The children were divided into two groups: those deemed eligible for GnRHa immediately, and those who needed more time due to "comorbid psychiatric problems and/or psychological difficulties." This second group did not receive any physical intervention and so serves as a comparison. The number in each group diminished considerably, for reasons which are not explained. After 18 months, only 71 children remained.

The group given GnRHa from 6 months onwards showed improvement by 18 months: the average CGAS score increased from 61 to 67 . This improvement is statistically significant $(P=$ .001), as the article emphasizes. However, these children also received psychological support, and so attributing this improvement to puberty suppression is unwarranted. The crucial comparison is between groups. ${ }^{4}$ By 18 months the group that did not receive GnRHa averaged a score of 63. As this group was selected from children with more serious psychological problems, it is hardly surprising that its score would be lower than the other group's. Anyway, this difference is not statistically significant: a two-tailed $t$-test for the difference between group 
means yields $P=.14$, far beyond the conventional .05 threshold. In sum, the samples were so small that we can draw no conclusions. Therefore the article provides no evidence that GnRHa improves psychosocial functioning.

\section{REFERENCES}

${ }^{1}$ Costa R, Dunsford M, Skagerberg E et al. Psychological support, puberty suppression, and psychosocial functioning in adolescents with gender dysphoria. J Sex Med 2015;12:2206-14.

${ }^{2}$ Butler G, de Graaf N, Wren B et al. Assessment and support of children and adolescents with gender dysphoria. Arch Dis Child 2018;103:631-6.

3 Heneghan C, Jefferson T. Gender-affirming hormone in children and adolescents. http://blogs.bmj.com/bmjebmspotlight/2019/02/25/gender-affirming-hormone-in-childrenand-adolescents-evidence-review/ (accessed September 1, 2019).

${ }^{4}$ Gelman A, Stern H. The difference between "significant" and "not significant" is not itself statistically significant. Am Stat, 2006;60:328-31. 